\title{
PASTEURIZAÇÃO DE LEITE NA PRÓPRIA EMBALAGEM EM BANHO-MARIA ${ }^{1}$
}

\author{
TEIXEIRA NETO, Rodrigo Otávio²; VAN DENDER, Ariene Gimenes Fernandes ${ }^{2}$; \\ BARBIERI, Margarida Kikuta ${ }^{2}$; EIROA, Mirtha Nelly Uboldi ${ }^{2} \&$ MOURA, Silvia Cristina S. Rolim $\mathrm{de}^{2}$
}

\section{RESUMO}

Amostras de leite de vaca embaladas em sacos de polietileno foram pasteurizadas em banho-maria a $65^{\circ} \mathrm{C}$ por 40 minutos. Os valores $\mathrm{F}\left(65,6^{\circ} \mathrm{C}\right)$ de pasteurização obtidos mantiveram-se dentro dos limites permitidos pela legislação brasileira, atestando a segurança do processo. Estudou-se a vida-de-prateleira em amostras de dois lotes diferentes do produto mantido, após a pasteurização, sob refrigeração à temperatura de abuso de $10^{\circ} \mathrm{C}$. Em um dos lotes chegou-se a um valor de 4 a 5 dias e no outro a um valor de 11 dias. Ambos são compativeis com a vida-de-prateleira obtida em produtos processados pelas tecnologias convencionais, o que soma positivamente na possibilidade de adoção desta tecnologia simples, para pequenas produções, pela legislação brasileira.

Palavras-chave: pasteurização, leite, vida-de-prateleira

\section{SUMMARY}

PASTEURIZATION OF PACKAGED MILK SUBMERGED IN A HOT WATER BATH. Samples of cow's milk, packaged in polyethylene bags, were pasteurized submerged in a hot water bath at $65^{\circ} \mathrm{C}$ for 40 minutes. The $F\left(65,6^{\circ} \mathrm{C}\right)$ values of pasteurization obtained were in the range admitted by the Brazilian legislation, giving evidence of the safety of the process. The shelf life of samples from two different batches was studied at the abuse temperature of $10^{\circ} \mathrm{C}$. In one batch the shelf life was 4 to 5 days and in the other 11 days. Both were consistent with the shelf life get in products processed by conventional technologies, summing up positively with the possibility of adoption by the Brazilian legislation of this simple technology for small processors.

Key words: pasteurization, milk, shelf life

\section{1 - INTRODUÇÃO}

O leite é uma fonte de nutrientes fundamentais ao homem, sendo por isso, universalmente, um dos alimentos de maior uso. Esta sua riqueza nutricional torna-o também um meio ideal para o desenvolvimento de microrganismos, que podem causar a sua deterioração em curto espaço de tempo, podendo também causar danos à saúde do homem quando contaminado por bactérias patogênicas.

Esta característica levou o homem, já há muito tempo, à preocupação com processos para possibilitar a sua conservação, destacando-se dentre eles os processos de pasteurização. AJZENTAL (1) fez uma breve e interessante revisão histórica dos esforços do homem neste sentido, de onde se depreende que os processos de pasteurização mais utilizados nos dias de hoje foram definidos durante a década de 30 e início da década de 40 .

\footnotetext{
1 Recebido para publicação em 20/02/97. Aceito para publicação em 26/05/97.

2 Pesquisadores Científicos do Instituto de Tecnologia de Alimentos. C.P. 139. CEP 13073-001. Campinas, SP.
}

A legislação brasileira (8) permite dois tipos de pasteurização: a lenta $\left(62-65^{\circ} \mathrm{C}\right.$ por 30 minutos) e a de curta duração $\left(72-75^{\circ} \mathrm{C}\right.$ por 15 a 20 segundos). O número de bactérias por mililitro de leite pasteurizado não deve ultrapassar $1,5 \times 10^{5}$ para o leite tipo $\mathrm{C}$, enquanto o número de termófilos e psicrotróficos deve ser inferior a $10 \%$ do número de mesófilos. Quanto à contaminação por microrganismos mesófilos a Divisão Nacional de Vigilância Sanitária de Alimentos(DINAL), do Ministério da Saúde, estabelece um limite máximo de $3 \times 10^{5} \mathrm{UFC} / \mathrm{ml}$ de leite pasteurizado tipo C (9).

Inúmeros trabalhos têm sido desenvolvidos para verificar a qualidade higiênico-sanitária do leite cru e pasteurizado $(2,3,4,6,11,18$,). A grande maioria destes trabalhos examina o leite pasteurizado pelos processos tradicionais admitidos pela legislação brasileira e, invariavelmente, têm apontado uma série de irregularidades nos resultados obtidos, demonstrando falhas na aplicação das tecnologias hoje disponíveis.

Por outro lado, em vários estados brasileiros, os produtores de leite têm introduzido, crescentemente, o leite pasteurizado na própria embalagem colocada em banho-maria a $65^{\circ} \mathrm{C}$ por 30 minutos. Na maioria dos estados não há normas que permitam o uso desta tecnologia, com exceção ao Estado de São Paulo (12) e ao Distrito Federal (13) que a admitem para a pasteurização de leite de cabra em pequenas produções.

Para este tipo de processo poucos trabalhos são encontrados na literatura. TEIXEIRA NETO et al. (15) e TEIXEIRA NETO \& VITALI (16) desenvolveram um equipamento e estudaram a pasteurização de leite de cabra, em banho-maria a $65^{\circ} \mathrm{C}$ por 40 minutos, demonstrando a viabilidade e segurança do processo, inclusive com relação ao desempenho da embalagem. SOUZA et al. (14) em estudo com leite bovino compararam a pasteurização lenta em banho-maria, com a de curta duração (rápida) em trocador de calor à placas. Não são dados detalhes dos tratamentos térmicos, fazendo-se supor que seguiram os tratamentos clássicos definidos na legislação brasileira. Dos resultados concluiram que o processo de rápido foi mais efetivo na diminuição da contagem microbiológica do que o processo lento em banho-maria; já quanto ao aspecto enzimático, ambos foram efetivos com relação à destruição da enzima fosfatase, mas com relação à enzima peroxidase, o processo rápido apresentou um número significativamente maior de amostras fora do padrão, comparado ao processo lento em banho-maria, indicando excesso de tratamento em mais de $70 \%$ das amostras, contra $20 \%$ das do processo lento.

É sabido que cerca de $30-40 \%$ do leite distribuído à população brasileira não é pasteurizado, ou seja, é distribuído na forma cru. Uma das razões para que isto aconteça parece ser a falta de tecnologia alternativa, simples e segu- 
ra, que permita aos pequenos produtores rurais pasteurizar o leite antes da sua entrega ao consumo. A partir do desenvolvimento de equipamento com estas características usado para a pasteurização de leite de cabra (16), pensou-se na possibilidade de estender o seu uso também para a pasteurização de leite bovino em pequena escala.

O objetivo do estudo foi verificar a viabilidade técnica da pasteurização do leite de vaca no protótipo disponível, medindo-se a eficácia da pasteurização e avaliando-se a vidade-prateleira do produto.

\section{2- MATERIAIS E MÉTODOS}

O protótipo de pasteurizador era constituído por um tanque de PVC de 200 litros, equipado com duas resistências elétricas de 3500 watts cada uma, bomba de circulação de água de 0,5HP, quatro cestos perfurados de alumínio, sensor de temperatura e alarmes, acoplados a um controlador com microprocessador e painel de controle. Maiores detalhes do equipamento são encontrados em (16).

A cada ensaio, aproximadamente 35 litros de leite de vaca foram coletados na plataforma de recepção da Cooperativa dos Produtores de leite da região de Campinas Ltda., em Jaguariúna-SP. No ITAL foram retiradas amostras para caracterização do produto cru, sendo o restante embalado em sacos plásticos de polietileno de baixa densidade, adequados para este procedimento (Matsuda Plásticos Ltda. Caieiras-SP), em unidades de 1 litro, as quais foram arranjadas em quatro cestos perfurados com capacidade de 8 litros cada um, perfazendo um total de 32 embalagens a ser pasteurizadas.

Foram realizados dois ensaios utilizando-se o seguinte procedimento: 1) a água do pasteurizador foi pré-aquecida a $75^{\circ} \mathrm{C}$; 2) os quatro cestos foram então colocados no pasteurizador; 3) acionou-se o controlador automático do processo; 4) a temperatura, que imediatamente após a introdução dos cestos no banho, caiu para $65^{\circ} 1^{\circ} \mathrm{C}$ foi mantida até soar o alarme do pasteurizador após 40 minutos; 5) imediatamente, os cestos foram transferidos para outro tanque com água corrente à temperatura ambiente, onde após cerca de 20 minutos completou-se o resfriamento do produto até cerca de $30^{\circ} \mathrm{C}$; e 6) as embalagens foram então retiradas dos cestos e armazenadas em câmara fria à temperatura de $10 \pm 1^{\circ} \mathrm{C}$.

Em cada cesto, na posição mais central, foi colocado um saquinho de leite com um termopar de cobre-constantan, com dispositivo especial para manter a sua extremidade de medida no ponto mais lento de penetração de calor(16). Foi também colocado um termopar diretamente na água, próximo ao bulbo do sensor de temperatura. Os termopares foram conectados a uma unidade de aquisição de dados Dianachart. As medidas de temperatura foram feitas a cada 30 segundos e os cálculos do valor $F$ de pasteurização foram feitos utilizando-se o método de PATASHNIK(10).

No primeiro ensaio foram separados para cada dia de avaliação grupos de 4 embalagens para análises de $\mathrm{pH}$, acidez, fosfatase, peroxidase, microbiológicas e sensoriais. Essas análises foram realizadas a zero, 4, 7, 11, 14 e 18 dias de estocagem. No segundo ensaio foram separados grupos de 5 embalagens para essas mesmas análises, as quais foram realizadas a zero, 4, 7 e 9 dias de estocagem, quando o estudo foi interrompido devido à deterioração microbiológica do produto.

As análises realizadas seguiram a seguinte metodologia:

- $\quad$ pH. Determinado em potenciômetro digital modelo B375 da Micronal(5).

- Acidez. Determinada segundo as Normas Analíticas do Instituto Adolfo Lutz(5).

- Fosfatase. Determinada pela ação dos comprimidos de Indo-phax e Phos-phax(5).

- Peroxidase. Determinada utilizando-se os reagentes de guaiacol $1 \%$ e água oxigenada 10 volumes(5).

- Contaminação por Salmonella, coliformes totais e fecais, mesófilos totais e psicrotróficos. Determinada seguindo a metodologia recomendada em VANDERZANT \& SPLITTSTOESSER(17).

- Sensorial. Amostras de leite pasteurizado, estocadas à temperatura de $10^{\circ} \mathrm{C}$, foram avaliadas sensorialmente por uma equipe de 9 julgadores treinados, utilizando-se escalas não estruturadas de $10 \mathrm{~cm}$, com pontos demarcados a $0,5 \mathrm{~cm}$ de cada extremidade, para a avaliação da intensidade de sabor de leite puro, intensidade de sabor de leite azedo e adequação para consumo (7). A cada época de análise, uma amostra de leite récem-processada foi apresentada aos julgadores para a rememorização das características do produto. $\mathrm{O}$ critério para o término do experimento foi definido para quando o ponto $5,0 \mathrm{~cm}$, correspondente à metade da escala utilizada, fosse atingido.

\section{3-RESULTADOS E DISCUSSÃO}

Os resultados das análises de caracterização do leite cru são apresentados na Tabela 1. Eles são normais para leite tipo C, devendo-se observar, no entanto, a elevada contagem de coliformes fecais e de microrganismos psicrotróficos no lote 2, comparado com o lote 1, demonstrando diferença sensível na condição higiênico-sanitária dos dois.

A Tabela 2 apresenta os resultados do valor $F\left(65,6^{\circ} \mathrm{C}\right)$ de pasteurização das amostras com termopar, para os ensaios do lote 1 e do lote 2 . Nos processos convencionais, admitidos pela legislação brasileira, os valores de $\mathrm{F}\left(65,6^{\circ} \mathrm{C}\right)$ devem estar, em sua grande maioria, na faixa de $5 \mathrm{~min}\left(62^{\circ} \mathrm{C}\right.$ por $30 \mathrm{~min})$ a $41 \mathrm{~min}\left(75^{\circ} \mathrm{C}\right.$ por $\left.20 \mathrm{~s}\right)$ para um valor $\mathbf{z}$ de $4,5^{\circ} \mathrm{C}$, não devendo, em qualquer hipótese, ser inferiores a $5 \mathrm{~min}$, pois isto representaria um subprocessamento. Como pode ser constatado pelos dados da Tabela 2 todos os valores são bem superiores a $5 \mathrm{~min}$ e encontram-se na faixa de tempos preconizada, atestando a adequação do tratamento térmico.

As curvas de penetração de calor que foram usadas nos cálculos dos valores $\mathrm{F}\left(65,6^{\circ} \mathrm{C}\right)$ da Tabela 2, são apresentadas na Figura 1. Nesta figura pode-se observar também o perfil de temperatura da água no banho-maria, proporcionando uma visão completa de todo o processo de pasteurização do leite. Vale destacar a pequena variação de temperatura entre as amostras colocadas em cestos diferentes, demonstrando a boa homogeneidade de tratamento propiciada pelo modelo protótipo de equipamento utilizado nos ensaios. 
TABELA 1. Análises de caracterização de leite de vaca cru, destinado ao processamento de leite tipo $\mathrm{C}$.

\begin{tabular}{lcc}
\hline \multicolumn{1}{c}{ Análises } & Lote 1 & Lote 2 \\
\hline densidade (g/cc) & 1,032 & 1,032 \\
$\mathrm{pH}$ & 6,65 & 6,76 \\
acidez ( ${ }^{\circ}$ Dornic) & 16,67 & 14,92 \\
extrato seco total (\%) & 12,05 & 12,31 \\
cinzas (\%) & 0,65 & 0,72 \\
gordura (\%) & 3,80 & 3,50 \\
nitrogênio total (\%) & 2,716 & 3,607 \\
nitrogênio não protéico (\%) & 0,190 & 0,185 \\
nitrogênio não caseinico (\%) & 0,77 & 0,89 \\
crioscopia ( ${ }^{\circ}$ Hortvert) & $-0,550$ & $-0,540$ \\
coliformes totais (NMP/ml) & $>240$ & $>240$ \\
coliformes fecais (NMP/ml) & 46 & $>240$ \\
mesófilos totais (UFC/ml) & $1,5 \times 10^{7}$ & $1,6 \times 10^{6}$ \\
Salmonella (em 25ml) & ausência & ausência \\
psicrotróficos (UFC/ml) & $3,4 \times 10^{4}$ & $9,5 \times 10^{5}$ \\
$\begin{array}{l}\text { Outros contaminantes: sangue, } \\
\text { pus, mastite, cloro, água } \\
\text { oxigenada e formol }\end{array}$ & ausência & ausência \\
\hline
\end{tabular}

TABELA 2. Valor $F\left(65,6^{\circ} \mathrm{C}\right)$, em minutos, na pasteurização de amostras de leite ensacadas e colocadas em banhomaria a $65^{\circ} \mathrm{C}$.

\begin{tabular}{lcccc}
\hline & Cesto 1 & Cesto 2 & Cesto 3 & Cesto 4 \\
\hline Lote 1 & 21,6 & 23,4 & 21,7 & 23,0 \\
Lote 2 & 28,4 & 35,1 & 30,1 & 30,6 \\
\hline
\end{tabular}

Os resultados das análises químicas, bioquímicas e microbiológicas após a pasteurização do leite são apresentados na Tabela 3. Pode-se verificar que os resultados são satisfatórios atestando a boa pasteurização. Observe-se, no entanto, que nas amostras pasteurizadas do lote 2, mesmo tendo sido atingidos valores de $\mathrm{F}$ maior, as contagens de mesófilos totais são bem mais elevadas quando comparadas com as das amostras do lote 1 , indicando a possível presença de um número maior de bactérias termicamente mais resistentes (termodúricas) no lote 2 .

Os resultados das análises de $\mathrm{pH}$ e acidez ao longo do estudo de vida-de-prateleira são apresentados na Tabela 4, onde pode-se observar uma alteração sensivel na acidez dos produtos após os 14 e 9 dias de estocagem, para as amostras do lote 1 e 2, respectivamente, indicando sua inadequação para consumo após estes períodos.

\section{Lote 1}

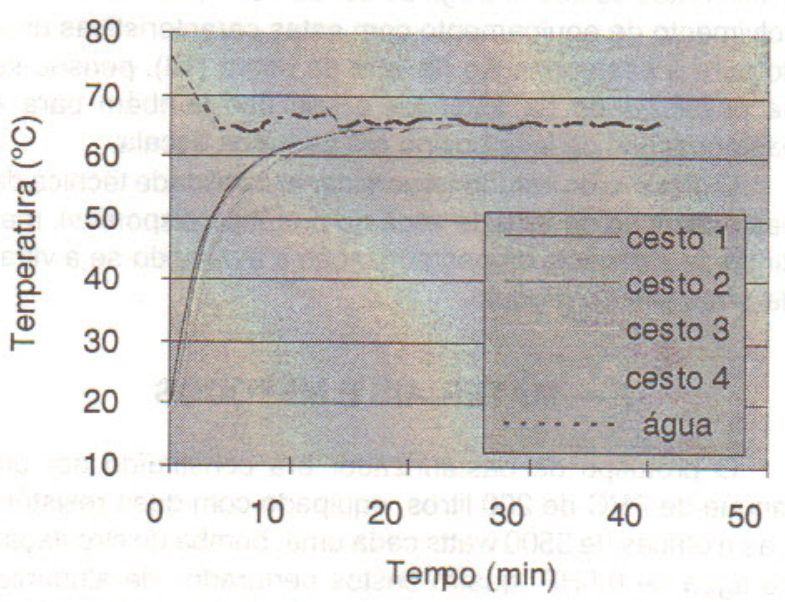

Lote 2

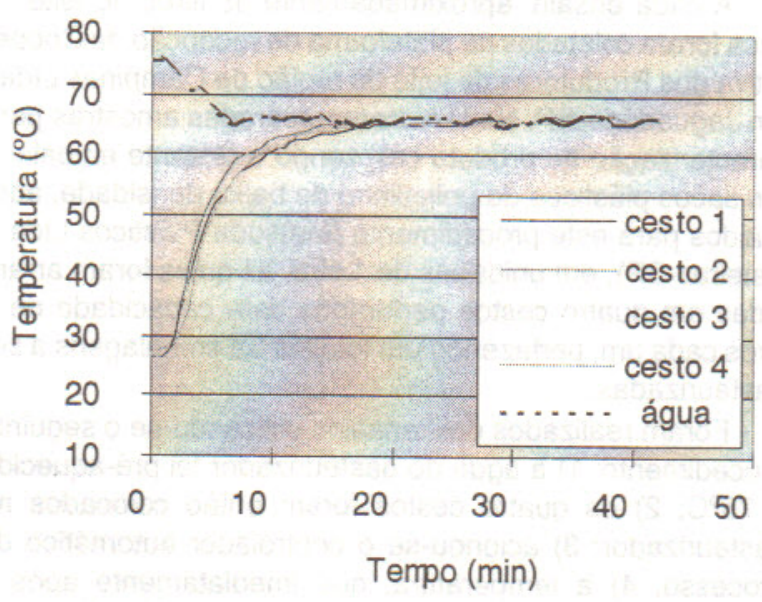

FIGURA 1. Curvas de penetração de calor em embalagens dos lotes 1 e 2 .

TABELA 3. Determinações físicas, químicas e microbiológicas no leite tipo C pasteurizado após embalagem.

\begin{tabular}{lcc}
\hline \multicolumn{1}{c}{ Análise } & Lote $1^{*}$ & Lote $2^{* *}$ \\
\hline $\mathrm{pH}$ & $6,60 \pm 0,01$ & $6,70 \pm 0,04$ \\
acidez & $16,67^{* \star *}$ & $15,32 \pm 0,22$ \\
peroxidase & positivo & positivo \\
fosfatase & negativo & negativo \\
coliformes totais (NMP/ml) & $<0,3$ & $<0,3$ \\
coliformes fecais (NMP/ml) & $<0,3$ & $<0,3$ \\
mesófilos totais (UFC/ml) & $1,6 \times 10^{2}$ & $5,9 \times 10^{3}$ \\
Salmonella (em 25ml) & ausência & ausência \\
psicrotróficos (UFC/ml) & $<10$ & $1,5 \times 10$ \\
\hline * médias de 4 amostras. & & \\
** médias de 5 amostras. & & \\
**medidas sem variação & &
\end{tabular}


TABELA 4. Determinações de pH e acidez de leite de vaca tipo $C$ pasteurizado, em função do tempo de estocagem a $10^{\circ} \mathrm{C}$.

\begin{tabular}{|c|c|c|c|}
\hline Lote & $\begin{array}{c}\text { Tempo de } \\
\text { estocagem (dias) }\end{array}$ & $2 \mathrm{pH}$ & $\begin{array}{c}\text { Acidez } \\
\text { ('Dornic) }\end{array}$ \\
\hline \multirow[t]{6}{*}{$1^{*}$} & zero & $6,60 \pm 0,01$ & $16,67^{\text {kkt}}$ \\
\hline & 04 & $6,62 \pm 0,03$ & $17,71 \pm 0,12$ \\
\hline & 07 & $6,61 \pm 0,03$ & $17,77 \pm 0,25$ \\
\hline & 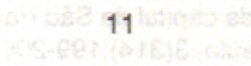 & $6,53 \pm 0,06$ & $16,75 \pm 0,49$ \\
\hline & 14 & $6,45 \pm 0,04$ & $18,49 \pm 0,94$ \\
\hline & and 18 & $6,50 \pm 0,11$ & $18,63 \pm 0,35$ \\
\hline & 21 & $6,5 \pm 0,03$ & $20,22 \pm 0,94$ \\
\hline $2^{* *}$ & zero & $6,70 \pm 0,04$ & $15,32 \pm 0,22$ \\
\hline & 04 & $6,77 \pm 0,01$ & $15,62 \pm 0,27$ \\
\hline \multirow[t]{2}{*}{ oxatsotit } & 07 & $6,70 \pm 0,07$ & $17,11 \pm 1,39$ \\
\hline & 09 & $6,56 \pm 0,04$ & $20,30 \pm 0,82$ \\
\hline
\end{tabular}

Os resultados das análises de microrganismos mesófilos totais e de psicrotróficos, ao longo do estudo de vida-deprateleira, são apresentados nas Tabelas 5 e 6 , respectivamente, para as amostras do lote 1 e nas Tabelas 7 e 8 para as amostras do lote 2 .

Os dados da Tabela 5 mostram que a população de microrganismos mesófilos totais elevou-se durante a estocagem refrigerada, atingindo aos 18 dias valores superiores a $10^{6} \mathrm{UFC} / \mathrm{ml}$. Ao mesmo tempo a contaminação de microrganismos psicrotróficos(Tabela 6) ganhou maior evidência aos 11 dias de estocagem a $10^{\circ} \mathrm{C}$, elevando-se até o $18^{\circ}$ dia quando foram atingidos níveis superiores a $10^{5} \mathrm{UFC} / \mathrm{ml}$.

TABELA 5. Microrganismos mesófilos totais $(\mathrm{UFC} / \mathrm{ml})^{\star} \mathrm{em}$ leite de vaca pasteurizado estocado a $10^{\circ} \mathrm{C}$ por 18 dias (lote 1).

\begin{tabular}{ccccccc}
\hline \multirow{2}{*}{ Amostras } & \multicolumn{6}{c}{ Tempo de armazenamento (dias) } \\
\cline { 2 - 6 } & 0 & 4 & 7 & 11 & 14 & 18 \\
\hline 1 & $4,7 \times 10^{2}$ & $1,2 \times 10^{2}$ & $7,0 \times 10^{1}$ & $2,0 \times 10^{2}$ & $8,0 \times 10^{5}$ & $1,3 \times 10^{6}$ \\
2 & $2,0 \times 10^{1}$ & $4,1 \times 10^{3}$ & $1,0 \times 10^{1}$ & $1,0 \times 10^{2}$ & $1,2 \times 10^{3}$ & $1,2 \times 10^{3}$ \\
3 & $4,0 \times 10^{1}$ & $2,1 \times 10^{3}$ & $1,0 \times 10^{1}$ & $2,1 \times 10^{3}$ & $7,6 \times 10^{2}$ & $1,8 \times 10^{6}$ \\
4 & $1,0 \times 10^{2}$ & $8,2 \times 10^{2}$ & $2,0 \times 10^{1}$ & $2,0 \times 10^{3}$ & $6,9 \times 10^{3}$ & $2,2 \times 10^{6}$ \\
\hline
\end{tabular}

* Unidades Formadoras de Colônias/ml.

TABELA 6. Microrganismos psicrotróficos (UFC/ml)* em leite de vaca pasteurizado estocado a $10^{\circ} \mathrm{C}$ por 18 dias (lote 1).

\begin{tabular}{ccccccc}
\hline \multirow{2}{*}{ Amostras } & \multicolumn{7}{c}{ Tempo de armazenamento (dias) } \\
\cline { 2 - 7 } & 0 & 4 & 7 & 11 & 14 & 18 \\
\hline 1 & $<10$ & $<10$ & $<10$ & $<10$ & $7,6 \times 10^{5}$ & $6,8 \times 10^{5}$ \\
2 & $<10$ & $<10$ & $<10$ & $<10$ & $1,1 \times 10^{3}$ & $1,1 \times 10^{1}$ \\
3 & $<10$ & $<10$ & $<10$ & $<10$ & $1,8 \times 10^{2}$ & $8,5 \times 10^{5}$ \\
4 & $<10$ & $<10$ & $<10$ & $1,3 \times 10^{3}$ & $3,6 \times 10^{3}$ & $9,3 \times 10^{5}$ \\
\hline
\end{tabular}

* Unidades Formadoras de Colônias/ml.
Considerando-se que para leite de vaca pasteurizado tipo C, a legislação federal vigente (Portaria DINAL 001 de 28.01.87) estabelece para a contagem padrão em placa um limite máximo de $3,0 \times 10^{5} \mathrm{UFC} / \mathrm{ml}, e$, considerando também a população de psicrotróficos observada, pode-se afirmar que, do ponto de vista microbiológico, as amostras do lote 1 conservaram-se em boas condições até 11 dias, estocadas a $10^{\circ} \mathrm{C}$.

Já os dados das Tabelas 7 e 8 mostram uma elevação mais acentuada das populações de microrganismos mesófilos e psicrotróficos durante a estocagem refrigerada, atingindo após 7 dias valores médios superiores a $10^{6} \mathrm{UFC} / \mathrm{ml}$ para microrganismos mesófilos totais e a $10^{5} \mathrm{UFC} / \mathrm{ml}$ para microrganismos psicrotróficos. Após 9 dias de estocagem o produto já estava totalmente deteriorado.

TABELA 7. Microrganismos mesófilos totais (UFC/ml)* em leite de vaca pasteurizado estocado a $10^{\circ} \mathrm{C}$ por 9 dias (lote 2).

\begin{tabular}{ccccc}
\hline \multirow{2}{*}{ Amostras } & \multicolumn{4}{c}{ Tempo de armazenamento (dias) } \\
\cline { 2 - 5 } & 0 & 4 & 7 & 9 \\
\hline 1 & $7,4 \times 10^{3}$ & $1,0 \times 10^{4}$ & $1,6 \times 10^{7}$ & deteriorado \\
2 & $3,8 \times 10^{3}$ & $3,0 \times 10^{4}$ & $7,3 \times 10^{5}$ & $>2,5 \times 10^{8}$ \\
3 & $1,0 \times 10^{4}$ & $7,2 \times 10^{3}$ & $2,1 \times 10^{6}$ & $4,5 \times 10^{7}$ \\
4 & $4,2 \times 10^{3}$ & $8,0 \times 10^{3}$ & $6,5 \times 10^{6}$ & $3,3 \times 10^{7}$ \\
5 & $4,0 \times 10^{3}$ & $3,1 \times 10^{3}$ & $7,0 \times 10^{5}$ & $2,5 \times 10^{7}$ \\
\hline
\end{tabular}

* Unidades Formadoras de Colônias/ml.

TABELA 8. Microorganismos psicrotróficos $(\mathrm{UFC} / \mathrm{ml})^{\star}$ em leite de vaca pasteurizado estocado a $10^{\circ} \mathrm{C}$ por 9 dias (lote 2).

\begin{tabular}{|c|c|c|c|c|}
\hline \multirow{2}{*}{ Amostras } & \multicolumn{4}{|c|}{ Tempo de armazenamento (dias) } \\
\hline & 0 & 4 & 7 & 9 \\
\hline 1 & $2 \times 10$ & $6 \times 10$ & $6,3 \times 10^{5}$ & deteriorado \\
\hline 2 & $1 \times 10$ & $2 \times 10^{3}$ & $1,0 \times 10^{5}$ & $2,7 \times 10^{7}$ \\
\hline 3 & $<10$ & $8,1 \times 10^{2}$ & $\begin{array}{l}\text { Tempo } \\
\text { (dias) }\end{array}$ & zxïzxïzxïzxï4 \\
\hline 4 & $<10$ & $1,1 \times 10^{2}$ & $1,0 \times 10^{6}$ & $2,8 \times 10^{7}$ \\
\hline 5 & $<10$ & $<10$ & $1,2 \times 10^{6}$ & $6,8 \times 10^{6}$ \\
\hline
\end{tabular}

*Unidades Formadoras de Colônias/ml.

Estas observações indicam que, do ponto de vista microbiológico, as amostras do lote 2 conservaram-se em boas condições de consumo até, no máximo, 4 a 5 dias quando estocadas $a 10^{\circ} \mathrm{C}$.

Paralelamente ao acompanhamento microbiológico foi feito um acompanhamento sensorial. Nas Tabelas 9 e 10 são apresentados os resultados obtidos para as amostras dos lotes 1 e 2, respectivamente, onde pode-se verificar que aos 18 dias de estocagem para as amostras do lote 1 e aos 7 dias para as do lote 2 , os três parâmetros avaliados pela equipe de julgadores ainda não tinham atingido o limite de aceitação estabelecido, muito embora tivessem sofrido alteração gradativa com o tempo de estocagem. Como, no 
entanto, neste mesmo período, a contagem de microrganismos já havia excedido os limites da legislação vigente para este tipo de produto, a avaliação sensorial foi encerrada. Assim sendo, a vida-de-prateleira do produto foi limitada por sua qualidade microbiológica e não pela qualidade sensorial.

TABELA 9. Avaliação sensorial de amostras de leite de vaca pasteurizado em função do tempo de estocagem a $10^{\circ} \mathrm{C}$ (lote 1).

\begin{tabular}{cccc}
\hline $\begin{array}{c}\text { Tempo } \\
\text { (dias) }\end{array}$ & $\begin{array}{c}\text { Sabor de } \\
\text { leite puro }\end{array}$ & $\begin{array}{c}\text { Sabor de } \\
\text { leite azedo }\end{array}$ & Consumo \\
\hline 0 & 9,5 & 0,3 & 9,7 \\
4 & 8,4 & 0,7 & 8,4 \\
7 & 7,7 & 1,4 & 8,0 \\
11 & 7,8 & 1,5 & 7,8 \\
14 & 7,5 & 1,7 & 7,7 \\
18 & 6,4 & 2,0 & 6,6 \\
\hline
\end{tabular}

TABELA 10. Avaliação sensorial de amostras de leite de vaca pasteurizado em função do tempo de estocagem a $10^{\circ} \mathrm{C}$ (lote 2).

\begin{tabular}{cccc}
\hline $\begin{array}{c}\text { Tempo } \\
\text { (dias) }\end{array}$ & $\begin{array}{r}\text { Sabor de } \\
\text { leite puro }\end{array}$ & $\begin{array}{c}\text { Sabor de } \\
\text { leite azedo }\end{array}$ & Consumo \\
\hline 0 & 8,6 & 0,7 & 8,5 \\
4 & 8,2 & 1,0 & 8,4 \\
7 & 6,5 & 1,8 & 6,4 \\
9 & $\mathrm{n}$ & $\mathrm{n}$ & $\mathrm{n}$ \\
\hline
\end{tabular}

$\mathrm{n}=$ não realizada a avaliação sensorial.

A diferença no resultado da vida-de-prateleira entre os dois lotes do produto evidencia a grande importância das condições higiênico-sanitárias da matéria-prima, pois o material do lote 2 apresentou contaminação inicial mais eleva$\mathrm{da}$, enquanto que o material do lote 1 apresentou-se em condições satisfatórias, o que praticamente dobrou a sua vida útil após a pasteurização e refrigeração. A elevação das contagens de bactérias psicrotróficas no lote 2 pode ter sido a maior responsável por este encurtamento na vida-de-prateleira do produto, pela ação das enzimas por elas produzidas.

\section{4- CONCLUSÃO}

Pode-se afirmar que o leite de vaca embalado e a seguir pasteurizado no protótipo desenvolvido, apresentou-se em boas condições de consumo, equivalente à dos processos convencionais. A vida-de-prateleira do produto foi definida pela sua condição microbiológica após a pasteurização e apresentou-se muito dependente da qualidade inicial higiênico-sanitária da matéria-prima, de tal forma que um dos lotes processado apresentou vida-de-prateleira de 4 a 5 dias e o outro de 11 dias, ambos estocados à $10^{\circ} \mathrm{C}$. Esses valores de vida-de-prateleira são também semelhantes aos obtidos para o leite de vaca tipo $\mathrm{C}$ pasteurizado pelos processos convencionais, indicando que as condições de comercialização e consumo poderão ser as mesmas.

\section{5-REFERÊNCIAS BIBLIOGRÁFICAS}

(1) AJZENTAL, A. Histórico do tratamento térmico do leite. Leite \& Derivados, São Paulo, 17(4):13-14, 1994.

(2) BARROS, V.R.M.; PANETTA, J.C. \& PERCES, E.M. do C. Eficiência do sistema de pasteurização utilizado em usinas de beneficiamento de leite da capital de São Paulo, Brasil. Higiene Alimentar, São Paulo, 3(314):199-206, 1984.

(3) COSTA, L.C.G.; CARVALHO, E.P.; BONNAS, D.S. OLIVEIRA JUNIOR, T.G. \& COSTA JUNIOR, L.C.G. Estudo da qualidade do leite cru e pasteurizado entregues na usina de beneficiamento em Lavras-MG: Aspectos microbiológicos. Rev. Inst. Latic. Candido Tostes, Juiz de Fora, 44(261-266):8-13, 1989.

(4) FROEDER, E.; PINHEIRO, A.J.R. \& BRANDĀO, S.C.C. Variação da qualidade microbiológica do leite cru tipo " $\mathrm{C}$ " da região de Viçosa. Rev. Inst. Latic. Candido Tostes, Juiz de Fora, 40(241):55-68, 1985.

(5) INSTITUTO ADOLFO LUTZ. Normas analíticas do Instituto Adolfo Lutz: métodos químicos e físicos para análise de alimentos. 2a. Ed. São Paulo, S.P. IAL, 1976.

(6) LIMA, M.da C., PINHEIRO, A.J.R. \& TEIXEIRA, M. A. Leite tipo C:1-Efeito de diferentes temperaturas de pasteurização sobre a flora normal do leite. Rev.Inst.Latic.Candido Tostes, Juiz de Fora, 47(279-281):41-45, 1992.

(7) MEILGAARD, M; CIVILLE, G.V. \& CARR, B.T. Sensory Evaluation Techniques, vol.II. CRC Press, Inc. Boca Raton, Flórida, USA, 1987. 159p.

(8) MINISTÉRIO DA AGRICULTURA-RIISPOA. Regulamento da Inspeção Industrial e Sanitária de Produtos de Origem Animal (aprovado pelo Decreto $n_{-} 30.691$, de $20 / 03 / 52$, alterado pelo Decreto $n_{-} 1.255$, de 25/06/52). Brasília, 1980. 66p.

(9) MINISTÉRIO DA SAÚDE - Divisão Nacional de Vigilância Sanitária de Alimentos(DINAL). Portaria $n^{2} 001$, de 28/01/87. Brasília, 1987.

(10) PATASHNIK, M.A. A simplified procedure for thermal process evaluation. Food Technol., Chicago, 7(1):1-6,1953.

(11) ROSSI JR., O.D.; NADER FILHO, A.; FALEIROS, R.R.; LOPES, J.L. \& SCHOCKEN-ITURRINO,R.P. Análises das condições físico-quimicas e bacteriológicas do leite oferecido ao comércio de Jaboticabal-SP. Rev. Inst. Latic. Candido Tostes, Juiz de Fora, 37(220):15-19, 1983.

(12) SECRETARIA DE AGRICULTURA E ABASTECIMENTO DO ESTADO DE SĀO PAULO (SAA/SP). Normas sobre a Produção de Leite de Cabra e seus Derivados em Condiçōes Artesanais. Resolução SAA-93, de 14/10/93. São Paulo, 1993.

(13) SECRETARIA DE AGRICULTURA DO DISTRITO FEDERAL (SADF). Portaria 002/95-SADF, de 10 de março de1995, publicada no Diário Oficial do Distrito Federal em 15 de março de 1995. Brasília, 1995.

(14) SOUZA, M.R.de; CERQUEIRA, M.M.de O.P.; SILVA, T.J.P.da; SILVA, A.N. da; RODRIGUES, R. \& SAMPAIO, I.B.M. Pasteurização lenta e rápida: uma avaliação de eficiência. Leite \& Derivados, São Paulo, 29(4):56-64, 1996. 
(15) TEIXEIRA NETO, R.O.; VAN DENDER, A.G.F.; GARCIA, E.E.C.: EIROA, M.N.U.; BARBIERI, M.K. \& MOURA, S.C.S.R. Pasteurização de leite de cabra por processo simplificado. Ciênc. Tecnol. Aliment., Campinas, 14(2):202-18, 1994.

(16) TEIXEIRA NETO, R.O. \& VITALI, A.A. Desenvolvimento de pasteurizador para leite embalado em sacos de polietileno. Ciênc. Tecnol. Aliment., Campinas, 15:(1):86-8, 1995.

(17) VANDERZANT, C. \& SPLITTSTOESSER, D.F. Compendium of Methods for the Microbiological Examination of Foods. American Public Health Association. Washington, 3rd ed. $1992,1219 p$.
(18) ZYLBERKAN, F., IZIDORO, V.L.B. \& BARROS, V.R.M. Condições bacteriológicas do leite pasteurizado (gordura $3,2 \%$ ) empacotado, em usina de beneficiamento da capital de São Paulo, durante o verão de 1983/84. Higiene Alimentar, São Paulo, 3(314):214-5, 1984.

\section{AGRADECIMENTOS}

Agradecemos ao CNPq e à Fundação de Desenvolvimento da Pesquisa Agropecuária-FUNDEPAG pelo apoio financeiro ao projeto e à Dra. Emilia Emico Miya Mori pelas sugestões na avaliação sensorial. 